\title{
N-M AND M-K RELATIONSHIPS OF REINFORCED CONCRETE COLUMNS IN TEC2018
}

\author{
Ayten GÜNAYDIN ${ }^{1,}$, Hande GÖKDEMIR ${ }^{1}$ \\ ${ }^{1}$ Eskişehir Osmangazi University, Department of Civil Engineering, Eskişehir, Turkey
}

\begin{abstract}
Reinforced concrete elements subject to moment, shear and axial force due to different level of static and dynamic loads based on their location and material characteristics. These elements disseminate the loads based on their connections with other elements. In particular, each column in the structure exhibits "combined bending" behavior together with the resulting moment of the eccentric axial force exerted. In the case of the axial load acting on one of the symmetry axes ( $x$ or $y$ axis) the uniaxial bending, and the axial load acting out of the symmetry axis, biaxial bending occurs. Also, since the structures are composed of two directional frames and slabs, the reinforced concrete columns are subject to combined bending effects in both directions. Therefore, the determination of the ultimate strength and behavior of the reinforced concrete columns depends on the interaction of axial force $(\mathrm{N})$ and moment $(\mathrm{M})$. In this study, the N-M diagram of reinforced concrete columns is given considering the section geometry, concrete and steel reinforcement strength and placement of the longitudinal reinforcements. The given N-M diagrams are prepared based on the axial force limits in codes. In addition, the N-e diagram showing the axial force and eccentricity relation of reinforced concrete column sections is given. Ductility ratios are given by plotting the moment curvature diagrams of the column sections at various axial force levels of the N-M diagram.
\end{abstract}

Keywords: N-M interaction diagram, Axial force, Eccentricity, Bending moment-curvature diagram

\section{INTRODUCTION}

One of the main tasks of columns and reinforced shear walls is to transfer the effects of the loads received from beams due to vertical and horizontal loads. This transfer occurs from column to column (or shear wall to shear wall) starting from the upper stories, and from basement columns (or shear walls) to the foundations. The main task of the designer and surely expectation of the user is to design the system, so that the columns can present a ductile behavior while transferring these loads. For this purpose, beam and column axes are supposed to be designed perpendicular to each other and meet in a junction. Otherwise, secondary beam alignment occurs, which is undesirable in a well designed system. The columns applied to the intersection of the beam axes should be arranged so that the stiffness and gravity centers are aligned with each other. In a reinforced concrete column, the ratio of the bending moment at gravity center to the axial force is defined as eccentricity (e) (Figure 1). Because of the fact that ' $\mathrm{e}$ ' is at a point far from the center of the cross section according to the definition, the moment acting on the cross section is transformed into the moment $\mathrm{M}=\mathrm{N} \cdot \mathrm{e}$ by moving the $\mathrm{N}$ to the gravity center. Balanced failure, which is the critical condition that determines the failure type in the columns; where the concrete in the outer layer of the compression zone is crushed and the reinforcement in the outer layer of the tension zone is yielded. Another definition is that there is a point that defines the small and large boundaries of eccentricity and this point is called balanced failure. In the column N-M diagram, the failure shape above the balanced failure case, in other words the small eccentric zone is called the brittle failure and the failure shape below the balance failure case, in other words large eccentric zone is called the ductile failure. Balanced failure in reinforced concrete columns, pure beam and column points and large and small eccentricities can be determined by drawing the N-M diagrams. Dimensionless N-M diagrams are used (Figure 1) to control the failure type of a dimensioned column or to achieve the desired failure type while designing. The balanced

*Corresponding Author:ayteng@ogu.edu.tr

Receiving Date: 06 March 2018 Publishing Date: 29 June 2018 
case in combined bending is directly dependent on eccentricity (e) and independent from reinforcement ratio. On the other hand, simple bending depends on reinforcement ratio.

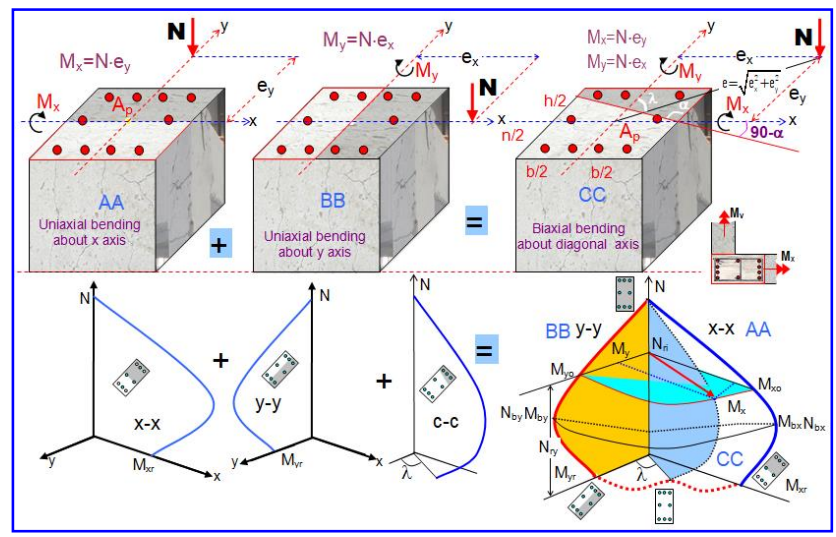

Figure1. Interaction diagram for compression plus biaxial bending

The ductile behavior of the columns is achieved not by the reinforcement ratio as in the beams but by the cross-section geometry, material strength, closely spaced ties and as symmetrical arrangements as possible (Figure 2). ACI [1], FEMA [2], EC8 [3], and TEC2007-2018 (Turkish Earthquake Code) predict that the reinforced concrete structures during the earthquake will initially damage the beams and reduces the earthquake energy and then damage the columns at a reduced level. In other words, they accept strong column-weak beam arrangements in designing the structures.

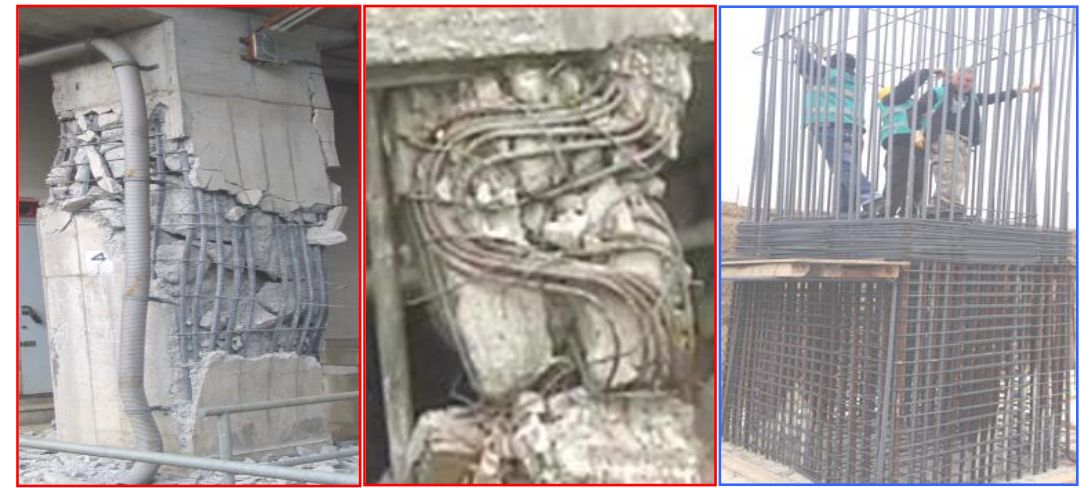

Figure 2. Damages of reinforced concrete columns and effect of reinforcement arrangements

Behaviors of reinforced concrete columns under biaxial bending and axial loads, and N-M interaction diagrams have been investigated experimentally and theoretically by many researchers. Furlong [6] tested reinforced concrete column specimens with biaxial bending and axial compression, and compared the experimental results with the theoretical method results. Hsu [7-9] presented experimental and theoretical studies to determine load-deformation behaviors of L-section, channel section and T-section reinforced concrete columns exposed to biaxial bending and axial loads. Rangan [10] proposed a method for the analysis of slender rectangular columns with uniaxial bending and under axial load. Additionally, earthquake loads apply horizontal when columns being vertical. Therefore, the parameters affecting the behavior of the columns increase considerably. As a result, codes change and improve with each code update due to the consequences of earthquake damages, increases in material strengths and new longitudinal and transverse reinforcement arrangements. 


\section{N-M INTERACTION DIAGRAM FOR REINFORCED CONCRETE COLUMN}

Reinforced concrete columns are subjected to biaxial bending and axial force with the effect of vertical and horizontal loads. Knowing the behavior under loads is critical for the analysis and design of reinforced concrete columns. By using the axial compression and moments effects, designers are able to determine the ultimate strength of the reinforced concrete columns. Therefore, the N-M interaction diagram should be drawn to determine the failure case and behavior for each column. Axial force and moment bearing capacities of reinforced concrete columns are depends on [11-13]:

1. Section geometry

2. Strength of concrete and reinforcement

3. Amount and placement of longitudinal and transverse reinforcements

N-M interaction diagrams are plotted based on the concrete compression block depth. Since the dots on the N-M diagram represent the ultimate strength, this curve characterizes the strength envelopes. It is possible to obtain the three dimensional interaction diagram by calculating $\mathrm{N}-\mathrm{M}$ diagrams for each direction of the column section. However, only the N-M diagrams of $\mathrm{x}-\mathrm{x}$ and $\mathrm{y}-\mathrm{y}$ axes are sufficient for design of the columns. Since TS500 [14] and TEC2007 [4] and TEC2018 [5] bring an upper limit on the amount of axial force that the column sections will be subjected to, the diagram suggests that the area of the region above these limits are not considered in the calculation. Even if the combined bending effects are within the diagram, the upper limit of the axial force of the codes must not be exceeded (Figure 3). Hence the column section can be enlarged, the longitudinal reinforcements can be increased or the applied loads can be reduced in new structures. In existing structures, the column sections can be enlarged by jacketing.

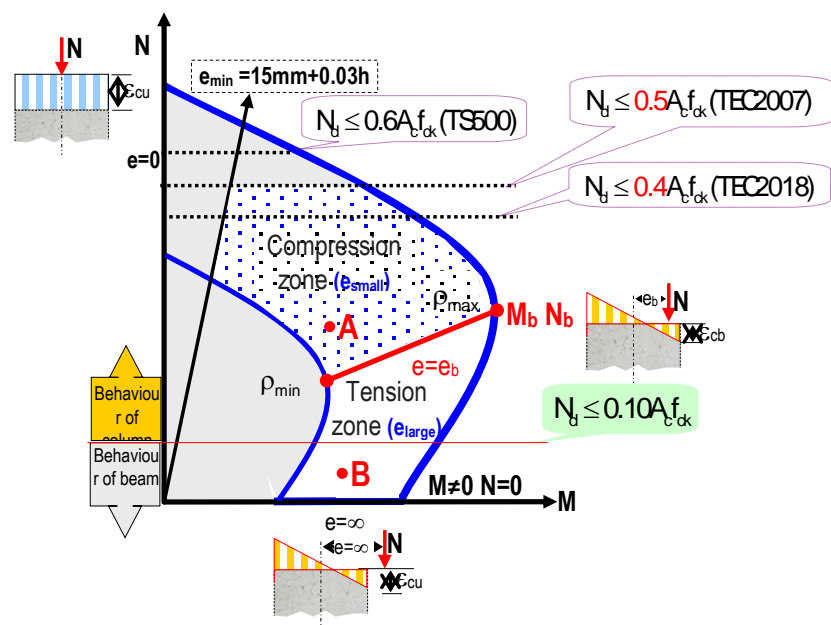

Figure 3. N-M interaction diagrams in columns

As can be seen Figure 3, the maximum moment corresponds to the point of balanced failure. Pure moment point corresponds to a balanced failure point of the beams. In combined bending, balanced failure depends on the axial load and eccentricity. Therefore, it is necessary to enlarge the crosssection or to confine the ties to prevent sudden breakage of the cross-section under combined bending. The interaction diagram obtained by setting the maximum and minimum limits specified in the codes for the column longitudinal reinforcement ratio gives more detailed information about the behavior of the cross section. If the minimum reinforcement ratio is used ductile failure occurs due to yielding of the reinforcement. On the other hand, if the maximum reinforcement ratio is used, brittle failure occurs due to early concrete fracture before yielding of the reinforcements. For a given section there are many kinds of interaction curves getting true the point $(\mathrm{N}-\mathrm{M})$ in sections diagrams with specified materials. There are various reinforcing arrangements to meet the strength demand of the cross section. Under the consideration of ductile failure requirements and minimum material consumption, if the 
eccentricity allows, reinforcement should be arranged to realize tension controlled failure or at least balanced failure as far as possible. When the values of $\mathrm{N}, \mathrm{M}$ can only lead to a compression controlled failure, it should also be considered firstly to adopt an effective reinforcement arrangement which means the minimum steel consumption [15].

TS500 [14] and TEC2007 [4] and TEC2018 [5] predict that the reinforcement ratio in the sections with biaxial bending and axial load should be minimum $\rho_{\min }=0.01$ and maximum $\rho_{\max }=0.04$. Therefore, as can also be seen from the interaction diagram of Figure 3, the biaxial bending effects are used for sections in the region and are not used out of safe region. If the reinforcement below the minimum reinforcement ratio is used, the column section will lose its load bearing capacity under ductile behavior due to insufficient strength. In case of using reinforcement greater than the maximum reinforcement ratio, the section loses its load bearing capacity with brittle failure caused by the crushing of the concrete since the reinforcement yield does not occur. If an N-M diagram of a certain cross section is plotted, the axial force and bending moment values taken from the load combinations are marked on the drawn N-M diagram. The cross-section behavior and failure case are determined according to the region where the marked point is located. For example, according to the determined values of $\mathrm{N}_{\mathrm{d}}$ and $\mathrm{M}_{\mathrm{d}}$, brittle failure occurs at the point $\mathrm{A}$ and ductile failure occurs at the point $\mathrm{B}$. As explained in TS500, the eccentricity of column equals to the bending moment to axial force ratio. The minimum eccentricity shall not be less than the value given by $e_{\min }=15^{\mathrm{mm}}+0,03 \mathrm{~h}$ (Figure 3 ).

\subsection{Determination of Plastic Centroid of Sections}

The eccentricity of a column load is the distance from the load to the plastic centroid of the column. The plastic centroid represents the location of the resultant force produced by the steel and the concrete. It is the point in the column cross section through which the resultant column load must pass to produce uniform strain at failure. For locating the plastic centroid, all concrete is assumed to be stressed in compression to $0.85 \mathrm{f}_{\mathrm{c}}$ and all steel to $\mathrm{f}_{\mathrm{y}}$ in compression. For symmetrical sections, the plastic centroid coincides with the centroid of the column cross section, while for nonsymmetrical sections; it can be located by taking moments (Figure 4) [16]. The plastic centroid of a rectangular section is calculated by Equation 1 according to the compression and tensile regions. If the cross section and the longitudinal reinforcement are symmetrical, the plastic centroid becomes $h / 2$.

$$
\mathrm{x}_{\mathrm{p}}=\frac{\left(0.85 \cdot \mathrm{f}_{\mathrm{cd}} \cdot \mathrm{bh}\right)(\mathrm{d}-\mathrm{h} / 2)+\left(\mathrm{A}_{\mathrm{s}} \cdot \mathrm{d}+\mathrm{A}_{\mathrm{s}^{\prime}} \cdot \mathrm{d}\right) \mathrm{f}_{\mathrm{yd}}}{\left(0.85 \cdot \mathrm{f}_{\mathrm{cd}} \cdot \mathrm{bh}\right)+\left(\mathrm{A}_{\mathrm{s}}+\mathrm{A}_{\mathrm{s}^{\prime}}\right) \cdot \mathrm{f}_{\mathrm{yd}}} \quad \mathrm{x}_{\mathrm{pp}}=\frac{\left(0.85 \cdot \mathrm{f}_{\mathrm{cd}} \cdot \mathrm{bh}\right)(\mathrm{d}-\mathrm{h} / 2)+\mathrm{A}_{\mathrm{s}^{\prime}} \cdot \mathrm{f}_{\mathrm{yd}} \cdot\left(\mathrm{d}-\mathrm{d}^{\prime}\right)}{\left(0.85 \cdot \mathrm{f}_{\mathrm{cd}} \cdot \mathrm{bh}\right)+\left(\mathrm{A}_{\mathrm{s}}+\mathrm{A}_{\mathrm{s}^{\prime}}\right) \cdot \mathrm{f}_{\mathrm{yd}}}
$$

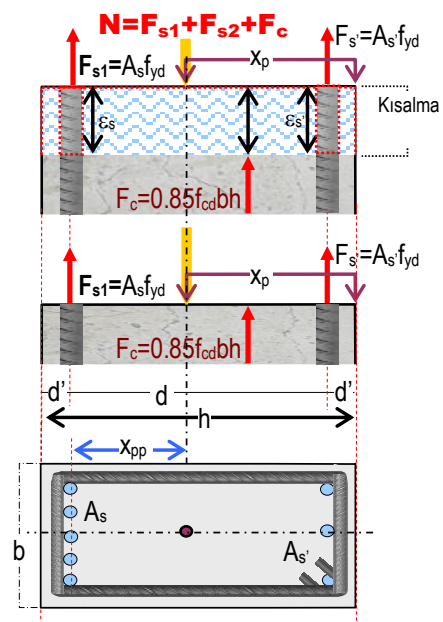

Figure 4. Plastic centroid for reinforced concrete rectangular section 


\subsection{Derivation of Equilibrium Equations}

Reinforced concrete columns are under biaxial bending effect due to combine with other structural elements, non-symmetric loads or structural systems and manufacturing requirements. The primary objective of the designer is to maximize the carrying capacity of the axial force and moment of the section. Uniaxial combined bending occurs if the bending moment and axial load apply on axis of symmetry in a section. If this bending moment and axial load are not on the axis of symmetry, biaxial combined bending occurs. Reinforced concrete columns under uniaxial bending effect are not encountered. Therefore, the systems solution is mostly based on the uniaxial combined bending criteria. The primary moment taken into account is in calculated direction and the moment perpendicular to same direction is not zero but small enough to be neglected. Biaxial bending problem known plastic centroid can be solved by two equilibrium and sufficient number of compatibility equations. Column sections with intermediate longitudinal reinforcements arise to accommodate the effects of the frames on the $\mathrm{x}$ and $\mathrm{y}$ axes. Otherwise, one side of the column will be weak as a result of not utilizing the reinforcement two sides of the column. The behavior of the reinforcements (yield cases), which are not parallel to the biaxial bending axis in columns, increases the number of unknown parameters in the equations to be solved.

The cross-sectional axial force is taken as axial force acting at a distance "e" from the plastic centroid. This axial force is multiplied by the distance "e" to take the moment. This is an application of shifting the force to a point. The number of compatibility equations depends on the order of reinforcements in the cross section (Figure 5). As shown in Figure 5, four compatibility equations must be written for four rows of reinforcements. Equilibrium and compatibility equations are given below in general terms. These equations can also be applied in rectangular sections.
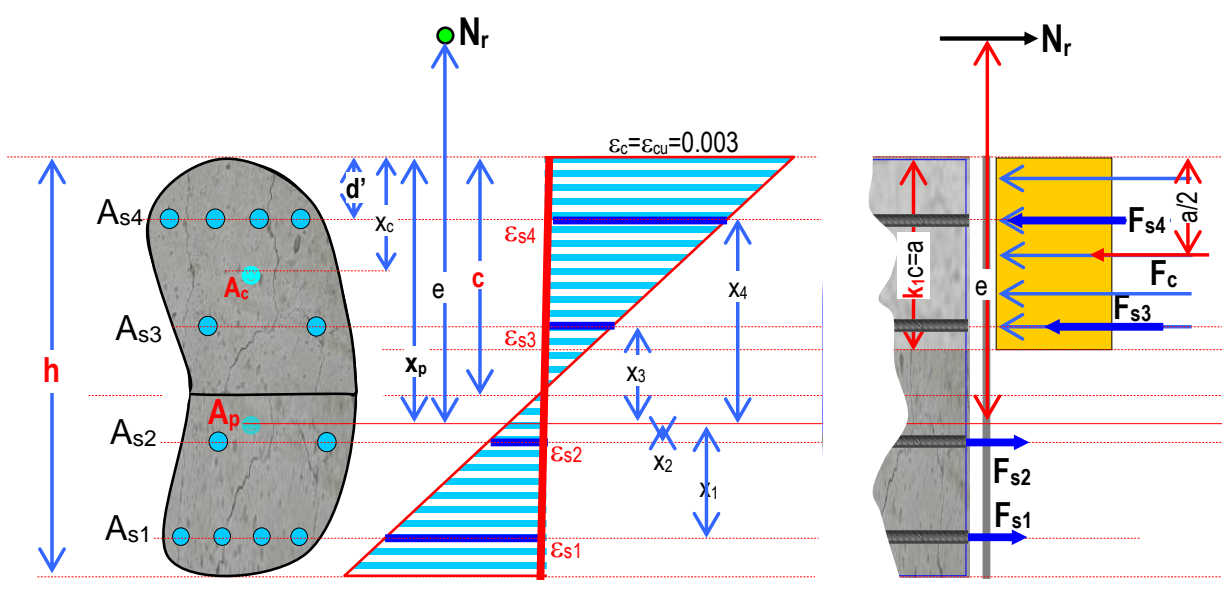

Figure 5. Internal strain distribution and forces in a column section

Maximum (pure) axial force carried by a column with intermediate reinforcement is calculated by Equation 2:

$$
\mathrm{N}_{\mathrm{or}}=\mathrm{F}_{\mathrm{c}}+\mathrm{F}_{\mathrm{s}}=0.85 \cdot \mathrm{f}_{\mathrm{cd}} \cdot\left(\mathrm{A}_{\mathrm{cc}}-\mathrm{A}_{\mathrm{st}}\right)+\mathrm{A}_{\mathrm{s}} \mathrm{f}_{\mathrm{yd}}
$$

The compatibility relations are written using strain distribution diagrams and stresses are given as follows:

$$
\varepsilon_{\mathrm{si}}=0.003 \frac{\left(\mathrm{x}_{\mathrm{p}}-\mathrm{c}\right)-\mathrm{x}_{\mathrm{i}}}{\mathrm{c}}\left|\sigma_{\mathrm{si}}\right| \leq \mathrm{f}_{\mathrm{yd}} \rightarrow \sigma_{\mathrm{si}}=\varepsilon_{\mathrm{si}} \cdot \mathrm{E}_{\mathrm{s}}=0.003 \cdot \mathrm{E}_{\mathrm{s}} \cdot\left(1+\frac{\left(\mathrm{x}_{\mathrm{i}}-\mathrm{x}_{\mathrm{p}}\right)}{\mathrm{c}}\right)
$$


The internal forces in the tensile zone are calculated by using the expressions given in Equation $3 \mathrm{~b}$ :

$$
\frac{0.003}{0.003+\varepsilon_{\mathrm{s}}}=\frac{\mathrm{c}=\left(\mathrm{a} / \mathrm{k}_{1}\right)}{\mathrm{d}} \Rightarrow \mathrm{a}=\frac{0.003 \cdot \mathrm{E}_{\mathrm{s}}}{0.003 \cdot \mathrm{E}_{\mathrm{s}}+\sigma_{\mathrm{s}}} \mathrm{k}_{1} \mathrm{~d} \rightarrow \sigma_{\mathrm{s}}=0.003 \cdot \mathrm{E}_{\mathrm{s}} \cdot \mathrm{k}_{1}\left[\frac{\mathrm{d}}{\mathrm{a}}-1\right] \leq \mathrm{f}_{\mathrm{yd}}
$$

The internal forces in the compression zone are calculated by using the expressions given in Equation 3c:

$$
\frac{\varepsilon_{\mathrm{s}^{\prime}}}{0.003}=\frac{\mathrm{c}-\mathrm{d}^{\prime}}{\mathrm{c}} \quad \varepsilon_{\mathrm{s}^{\prime}}=0.003 \cdot\left[\frac{\mathrm{a}-\mathrm{k}_{1} \mathrm{~d}}{\mathrm{a}}\right] \rightarrow \sigma_{\mathrm{s}^{\prime}}=0.003 \cdot \mathrm{E}_{\mathrm{s}}\left[1-\mathrm{k}_{1} \frac{\mathrm{d}^{\prime}}{\mathrm{a}}\right] \leq \mathrm{f}_{\mathrm{yd}}
$$

After the internal forces are found for the concrete and reinforcement, the axial force is calculate from the equilibrium equation to be written in the section and the ultimate moment is obtained by taking the moment with respect to the plastic centroid found by Equilibrium 1. The axial force and moment that the section carries calculate by Equation 4. is given as follows:

$$
\left.\begin{array}{l}
\mathrm{N}_{\mathrm{r}}=\mathrm{F}_{\mathrm{c}}+\mathrm{F}_{\mathrm{s}}=\mathrm{F}_{\mathrm{c}}+\mathrm{F}_{\mathrm{s}-\mathrm{basm}}-\mathrm{F}_{\mathrm{s}-\mathrm{cekme}}=0.85 \cdot \mathrm{f}_{\mathrm{cd}} \cdot \mathrm{A}_{\mathrm{cc}}+\sum \mathrm{A}_{\mathrm{s}} \mathrm{f}_{\mathrm{yd}}-\sum \mathrm{A}_{\mathrm{s}} \mathrm{f}_{\mathrm{yd}} \\
\mathrm{M}_{\mathrm{r}}=\mathrm{N}_{\mathrm{r}} \cdot \mathrm{e}=\mathrm{F}_{\mathrm{c}} \cdot\left(\mathrm{x}_{\mathrm{p}}-\mathrm{a} / 2\right)+\mathrm{F}_{\mathrm{si}} \cdot \mathrm{x}_{\mathrm{i}}=0.85 \cdot \mathrm{f}_{\mathrm{cd}} \cdot \mathrm{A}_{\mathrm{cc}}\left(\mathrm{x}_{\mathrm{p}}-\mathrm{a} / 2\right)+\mathrm{F}_{\mathrm{sl}} \cdot \mathrm{x}_{1}+\mathrm{F}_{\mathrm{s} 2} \cdot \mathrm{x}_{2}+\mathrm{F}_{\mathrm{s} 3} \cdot \mathrm{x}_{3}+\mathrm{F}_{\mathrm{s} 4} \cdot \mathrm{x}_{4} \\
\mathrm{M}_{\mathrm{r}}=0.85 \cdot \mathrm{f}_{\mathrm{cd}} \cdot \mathrm{A}_{\mathrm{cc}}\left(\mathrm{x}_{\mathrm{p}}-\mathrm{a} / 2\right)+\mathrm{A}_{\mathrm{s} 1} \cdot \mathrm{f}_{\mathrm{yd} 1} \cdot \mathrm{x}_{1}+\mathrm{A}_{\mathrm{s} 2} \cdot \mathrm{f}_{\mathrm{yd} 2} \cdot \mathrm{x}_{2}+\mathrm{A}_{\mathrm{s} 3} \cdot \mathrm{f}_{\mathrm{yd} 3} \cdot \mathrm{x}_{3}+\mathrm{A}_{\mathrm{s} 4} \cdot \mathrm{f}_{\mathrm{yd} 4} \cdot \mathrm{x}_{4}
\end{array}\right\}
$$

If there is only compression and tension reinforcement, the above equations can be rearranged by removing other reinforcements. There are only four equations although there are five $\left(\mathrm{N}_{\mathrm{r}}, \mathrm{e}, \mathrm{a}, \sigma_{\mathrm{s}}\right.$ and $\left.\sigma_{\mathrm{s}}\right)$ unknown parameters to solve the above equations. Therefore, an additional equation can be written as equilibrium of the reinforcement where the compression reinforcement yields. The reinforcements added are arranged on the far sides of the column sections to increase the moment carrying capacity of the sections. In rectangular sections, reinforcement arrangements are also very effective in addition to the amount of reinforcement. In columns with middle reinforcement, the moment carrying capacity is small due to the closeness to the neutral axis. However, middle reinforcement with ties increases the axial load carrying capacity due to the increase of the core concrete area. So, middle reinforcement is not unnecessary. Due to these effects, the most commonly used section in practice is rectangular sections with reinforcement distributed through the edges.

\section{TURKISH EARTHQUAKE CODE (TEC2018)}

In TEC2018, the simplified ultimate strengths in axial compression $\left(\mathrm{N}_{\mathrm{or}}\right)$ and tension strength $\left(\mathrm{N}_{\mathrm{tr}}\right)$ for the column and shear wall sections are given by Equation 5 .

$$
\mathrm{N}_{\mathrm{or}}=0.85 \mathrm{f}_{\mathrm{cd}}\left(\mathrm{A}_{\mathrm{g}}-\mathrm{A}_{\mathrm{st}}\right)+\mathrm{A}_{\mathrm{st}} \mathrm{f}_{\mathrm{yd}} \quad \mathrm{N}_{\mathrm{tr}}=\mathrm{A}_{\mathrm{st}} \mathrm{f}_{\mathrm{yd}}
$$

where $\mathrm{A}_{\mathrm{g}}$ is the cross-sectional area of the column, and $\mathrm{A}_{\mathrm{st}}$ is the total longitudinal reinforcement area in the column section. The compression force $\left(\mathrm{N}_{\mathrm{br}}\right)$ and bending moment $\left(\mathrm{M}_{\mathrm{br}}\right)$ values corresponding to the balanced case in the column and shear wall sections are calculated by Equation (6). The $A_{\text {su }}$ value is the sum of the areas of the outermost row longitudinal reinforcement in the direction considered in the column section or the sum of the longitudinal reinforcement areas in the end zone in the section of the shear wall. Similarly, $A_{\mathrm{sg}}$ is the sum of the areas of the inner row longitudinal reinforcement in the direction considered in the column section or the sum of the areas of longitudinal reinforcement in the body section of the shear wall (Figure 6). The sum of the $A_{\text {su }}$ and $A_{\text {sg }}$ values is equal to the total of the reinforcement area in the column or shear wall sections. Axial compression force under vertical loads in column and shear wall sections shall not be greater than $\mathrm{N}_{\mathrm{d}, \max }=0.40 \mathrm{f}_{\mathrm{ck}} \mathrm{bh}$ and $\mathrm{N}_{\mathrm{d}, \max }=0.25 \mathrm{f}_{\mathrm{ck}} \mathrm{bh}$ respectively 


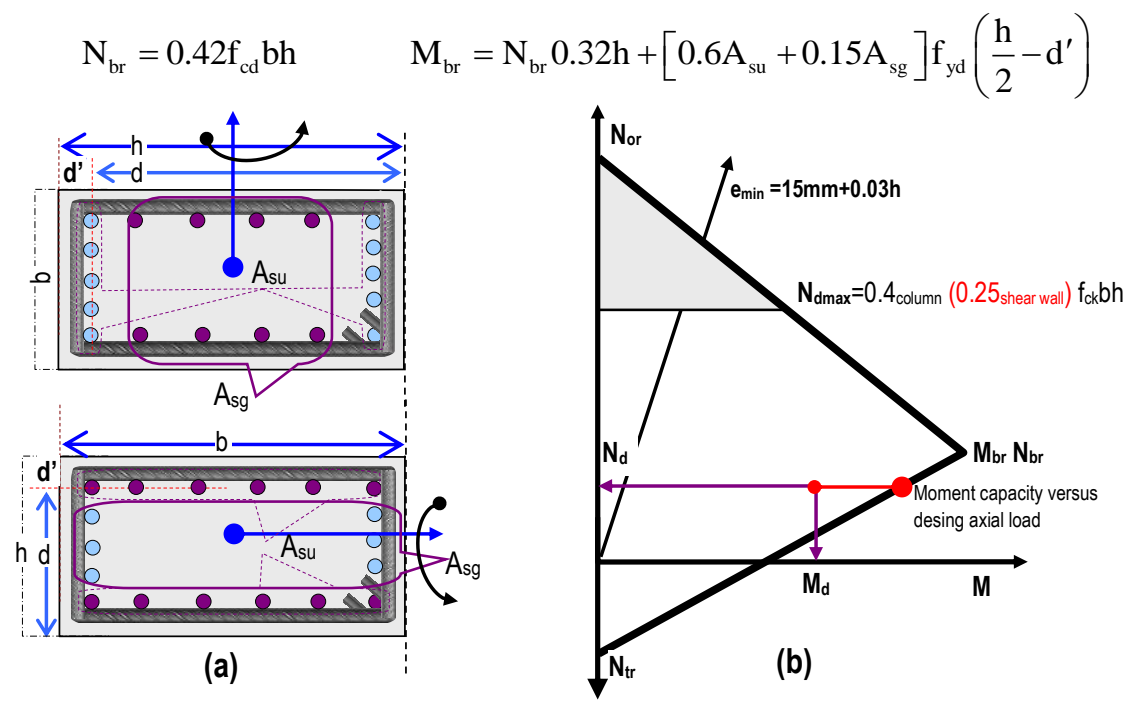

Figure 6. Design N-M interaction diagrams in columns [5]

The design bending moment $\left(\mathrm{M}_{\mathrm{d}}\right)$ obtained from the analysis in the column and shear wall sections shall satisfy the condition given by Equation 7. For both cases where the design compression force is greater than the equilibrium compression force $\left(\mathrm{N}_{\mathbb{d}} \geq \mathrm{N}_{\mathrm{r}}\right)$ and smaller than the equilibrium compression force $\left(\mathrm{N}_{\mathrm{d}} \leq \mathrm{N}_{\mathrm{r}}\right)$ (Figure 6).

$$
\left(\mathbf{N}_{\mathrm{d}} \geq \mathbf{N}_{\mathrm{r}}\right) \rightarrow \mathrm{M}_{\mathrm{d}} \leq \mathrm{M}_{\mathrm{r}}=\frac{\mathrm{N}_{\mathrm{or}}-\mathrm{N}_{\mathrm{d}}}{\mathrm{N}_{\mathrm{or}}-\mathrm{N}_{\mathrm{br}}} \mathrm{M}_{\mathrm{br}} \quad\left(\mathbf{N}_{\mathrm{d}} \leq \mathbf{N}_{\mathrm{r}}\right) \rightarrow \mathrm{M}_{\mathrm{d}} \leq \mathrm{M}_{\mathrm{r}}=\frac{\mathrm{N}_{\mathrm{d}}+\mathrm{N}_{\mathrm{tr}}}{\mathrm{N}_{\mathrm{br}}+\mathrm{N}_{\mathrm{tr}}} \mathrm{M}_{\mathrm{br}}
$$

The condition given by Equation (8) should be provided in the corner columns.

$$
\frac{\left(M_{d}\right)_{x}}{\left(M_{r}\right)_{x}}+\frac{\left(M_{d}\right)_{y}}{\left(M_{r}\right)_{y}} \leq 1.0
$$

\section{NUMERICAL EXAMPLES FOR N-M INTERACTION DIAGRAM}

The N-M interaction diagrams for the $\mathrm{x}$ and $\mathrm{y}$ directions of a column sections are plotted and values are calculated at selected points. The concrete and steel grades are C25/30 and B 420C. Section dimensions, reinforcement arrangement, strain distribution diagram in $\mathrm{x}$ and y directions, and internal forces are shown in Figure 7.

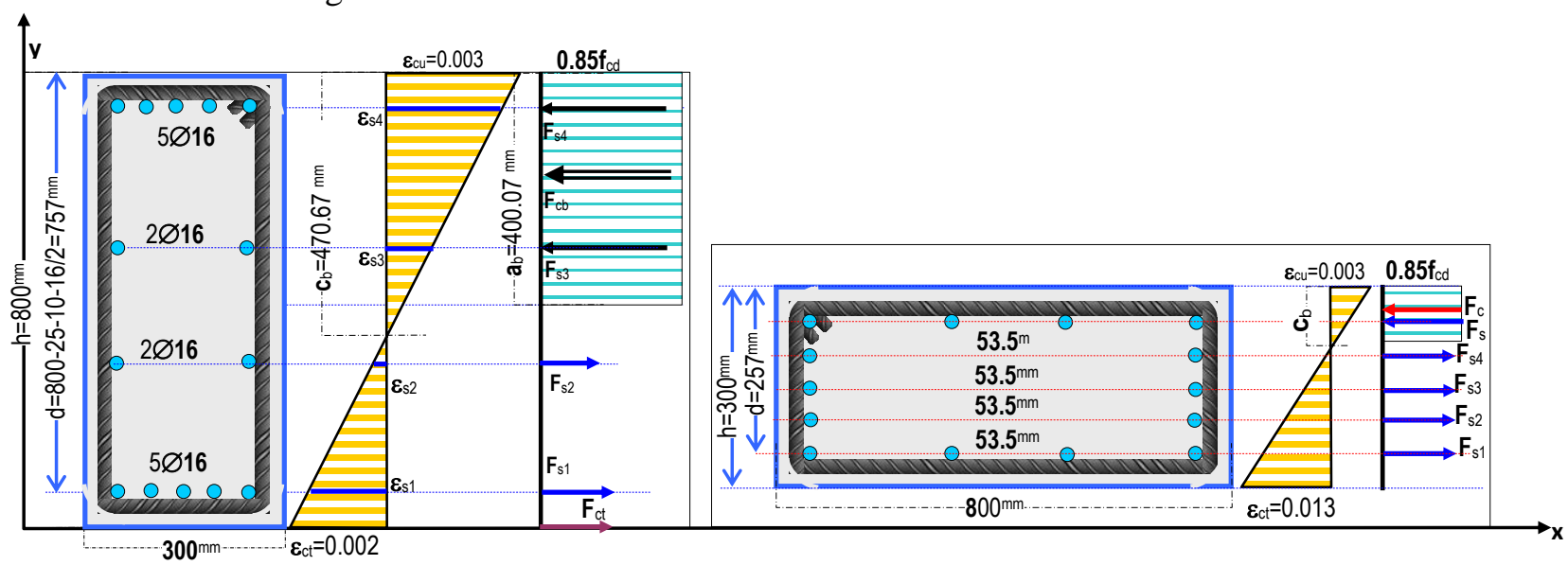

Figure 7. Section properties, internal strain distributions forces 
Günaydın and Gökdemir / Anadolu Univ. J. of Sci. and Technology A - Appl. Sci. And Eng. 19 (2) - 2018

Pure compression and tensile forces of the column section are calculated for both directions as follows:

Pure compression $\mathrm{N}_{\text {or }}=0.85 \mathrm{f}_{\mathrm{cd}} \mathrm{bh}+\sum_{\mathrm{i}=1}^{\mathrm{N}} \mathrm{A}_{\mathrm{si}} \mathrm{f}_{\mathrm{ydi}}=0.85 \cdot 0.0167 \cdot(300 \cdot 800-14 \cdot 201)+0.365 \cdot 14 \cdot 201=4387.92 \mathrm{kN}$ Pure tension $\mathrm{N}_{\mathrm{tr}}=-0.85 \mathrm{f}_{\mathrm{ctd}} \mathrm{bh}-\sum_{\mathrm{i}=1}^{\mathrm{N}} \mathrm{A}_{\mathrm{si}} \mathrm{f}_{\mathrm{ydi}}=-0.85 \cdot 0.00117 \cdot(300 \cdot 800-14 \cdot 201)-0.365 \cdot 14 \cdot 201=-1262.32 \mathrm{kN}$

Strains in steel for the balanced case and the axial load and moment values corresponding to this point are calculated as follows for the $\mathrm{x}$ direction:

$$
\begin{aligned}
& \frac{\mathrm{c}_{\mathrm{b}}}{\mathrm{h}-\mathrm{d}^{\prime}}=\frac{0.003}{\varepsilon_{\mathrm{sy}}+0.003} \Rightarrow \mathrm{c}_{\mathrm{b}}=\varepsilon_{\mathrm{cu}} \frac{\mathrm{h}-\mathrm{d}^{\prime}}{\varepsilon_{\mathrm{sy}}+\varepsilon_{\mathrm{cu}}}=0.003 \frac{800-43}{0.001825+0.003}=470.67 \quad \mathrm{k}_{1} \mathrm{c}_{\mathrm{b}}=0.85 \cdot 470.67=400.07 \\
& \varepsilon_{\mathrm{s} 1}=\frac{0.003 \cdot(757-470.67)}{470.67}=0.001825>\varepsilon_{\mathrm{sy}} \Rightarrow \mathrm{F}_{\mathrm{s} 1}=\mathrm{F}_{\mathrm{s} 4}=(5 \cdot 201 \cdot 365) 10^{-3}=366.83 \mathrm{kN} \quad \mathrm{F}_{\mathrm{s} 2}=15.03 \mathrm{kN} \\
& \mathrm{N}_{\mathrm{br}}=\mathrm{F}_{\mathrm{s}}+\mathrm{F}_{\mathrm{c}}=[366.825+87.63-15.03-366.825]+0.85 \cdot 16.67 \cdot 300 \cdot 400.07 \cdot 10^{-3}=1773.24 \mathrm{kN} \\
& \mathrm{M}_{\mathrm{br}}=\left(0.85 \cdot 16.67 \cdot 300 \cdot 400.07\left[\frac{800}{2}-\frac{400.07}{2}\right] 10^{-6}+[2 \cdot 366.825 \cdot(400-43)+(87.63+15.03) \cdot 100] 10^{-3}\right)=612.31 \mathrm{kNm}
\end{aligned}
$$

Similarly, Strains in steel for the balanced case for y direction and the axial load and moment values corresponding to this point are calculated as follows:

$$
\begin{aligned}
& \frac{0.003}{\mathrm{c}_{\mathrm{b}}}=\frac{\varepsilon_{\mathrm{sy}}}{\mathrm{d}-\mathrm{c}_{\mathrm{b}}} \Rightarrow \quad \varepsilon_{\mathrm{sy}}=0.001825 \rightarrow \mathrm{c}_{\mathrm{b}}=159.80^{\mathrm{mm}} \quad \mathrm{k}_{1} \mathrm{c}_{\mathrm{b}}=0.85 \cdot 159.80=135.82^{\mathrm{mm}} \\
& \varepsilon_{\mathrm{s} 5}=\frac{0.003 \cdot(159.80-43)}{159.80}=0.0022<\varepsilon_{\mathrm{sy}} \rightarrow \mathrm{F}_{\mathrm{s} 5}=(4 \cdot 201 \cdot 365) 10^{-3}=293.46 \mathrm{kN}=\mathrm{F}_{\mathrm{s} 1} \\
& \mathrm{~F}_{\mathrm{s} 4}=95.54 \mathrm{kN} \quad \mathrm{F}_{\mathrm{s} 3}=14.79 \mathrm{kN} \mathrm{F}_{\mathrm{s} 2}=65.96 \mathrm{kN} \quad \mathrm{G} 555555551555.555555555 \mathrm{H} \\
& \mathrm{N}_{\mathrm{br}}=\mathrm{F}_{\mathrm{s}}+\mathrm{F}_{\mathrm{c}}=\left[293.46+95.54+14.79-65.96-293.42+0.85 \cdot 16.67 \cdot 800 \cdot 135.82 \cdot 10^{-3}=1584.01 \mathrm{kN}\right. \\
& \mathrm{M}_{\mathrm{br}}=\left(1539.60\left[\frac{300}{2}-\frac{135.82}{2}\right] 10^{-6}+[(293.46+293.42) \cdot(150-43)] 10^{-3}+[(95.54+65.96) \cdot(53.5)] 10^{-3}\right) \\
& \mathrm{M}_{\mathrm{br}}=197.82 \mathrm{kNm}
\end{aligned}
$$

For the given column cross section, the axial load and moment values are calculated and N-M interaction diagrams are plotted on the figure below (Figure 8). In Figure 8, point A shows the pure bending point corresponding to $\mathrm{N}=0$ and $\mathrm{M} \neq 0$, the point $\mathrm{B}$ shows balanced failure case, the point $\mathrm{C}$ shows maximum axial force upper limit in TEC2018

$\mathrm{N}_{\mathrm{d}}=0.40 \cdot \mathrm{f}_{\mathrm{ck}} \cdot \mathrm{b} \cdot \mathrm{h}=(0.40 \cdot 25 \cdot 300 \cdot 800) 10^{-3}=2400 \mathrm{kN}$, the point $\mathrm{D}$ shows maximum axial force upper limit in TEC2007 $\mathrm{N}_{\mathrm{d}}=0.50 \cdot \mathrm{f}_{\mathrm{ck}} \cdot \mathrm{b} \cdot \mathrm{h}=(0.50 \cdot 25 \cdot 300 \cdot 800) 10^{-3}=3000 \mathrm{kN}$, and the point $\mathrm{E}$ shows the maximum axial force upper limit in $\operatorname{TS}_{500} \mathrm{~N}_{\mathrm{d}}=0.90 \cdot \mathrm{f}_{\mathrm{ck}} \cdot \mathrm{b} \cdot \mathrm{h}=(0.90 \cdot 16.67 \cdot 300 \cdot 800) 10^{-3}=3600 \mathrm{kN}$. 


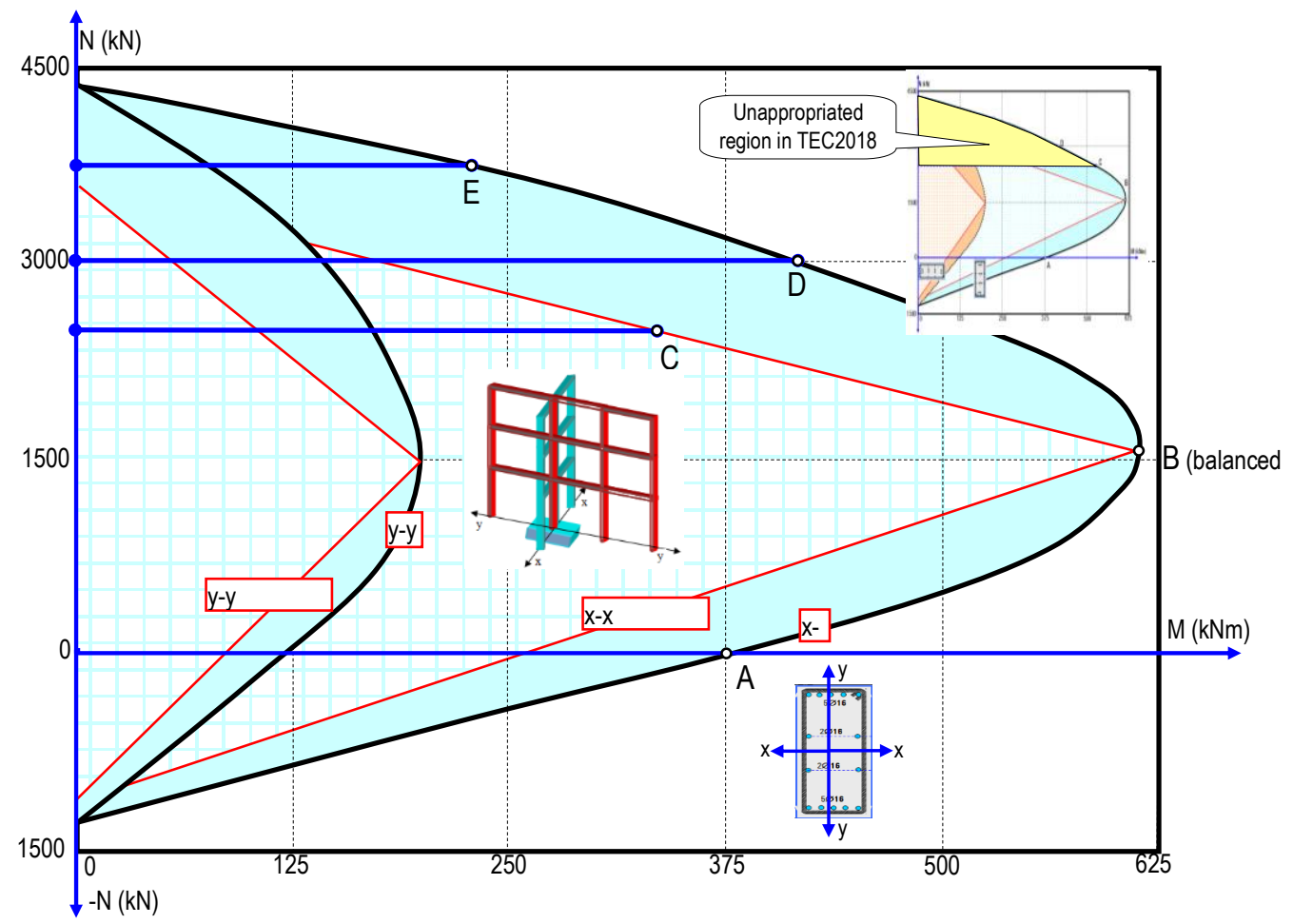

Figure 8. Interaction diagrams for combined axial and bending loads

In Figure 8, which summarizes the behavior of reinforced concrete column sections, the N-e diagram can be plotted instead of the N-M diagram. This N-e diagram is used for determining the dimensions of the columns. In the $\mathrm{N}$-e diagram, the region above the balanced failure line (corresponding to the compression region in the N-M diagram) is called the small eccentricity region, and below the balanced failure line (corresponding to the tensile region in the N-M diagram) is called the large eccentricity region. If the eccentricity is negative, then the tensile axial force is present. This is mostly seen in the edge columns during the earthquakes.

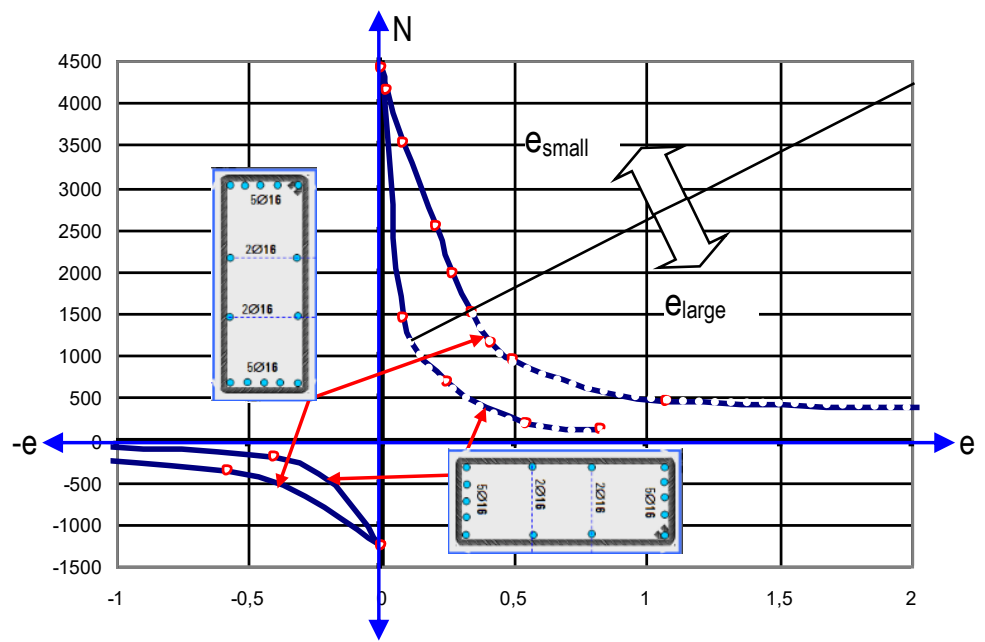

Figure 9. Interaction dią-N ; under axial loads for different eccentricities

Due to the fact that the longitudinal reinforcements in the column sections are not symmetrical and the beams are not supported by columns at the end region in the edge and corner columns causes N-M diagram being not symmetrical. This situation is not desirable, especially since it affects the behavior of the building during an earthquake. In addition, the non-symmetrical arrangement of the longitudinal reinforcements in the column sections will cause a switch between compression and tension regions 
under earthquake loads. Moment bearing capacity is changed due to the change of the position of the plastic centroid of the sections. This situation is clearly seen in Figure 10 obtained from the for both symmetrical and non-symmetrical reinforcement arrangements in column sections.

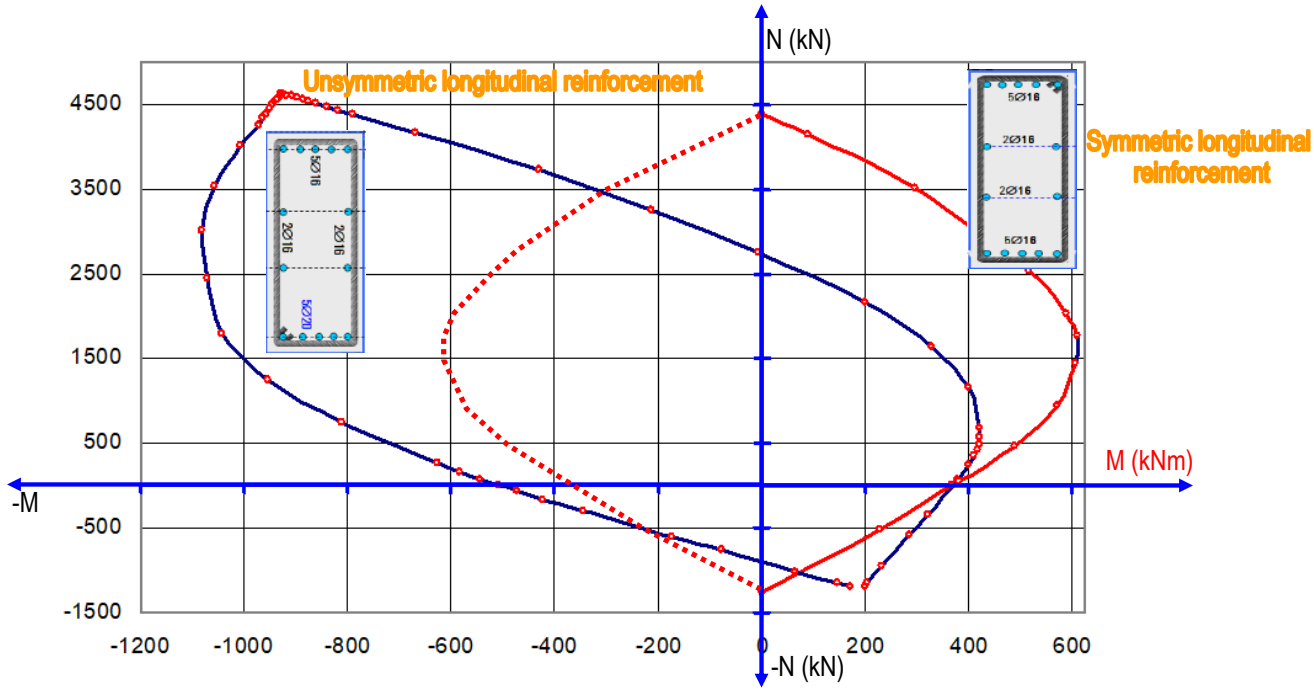

Figure 10. Symmetric and unsymmetric interaction diagrams for combined axial and bending loads

N-M diagrams for non-symmetrical longitudinal reinforcement arrangements and eccentricity with respect to different concrete classes were obtained as follows (Figure 11).
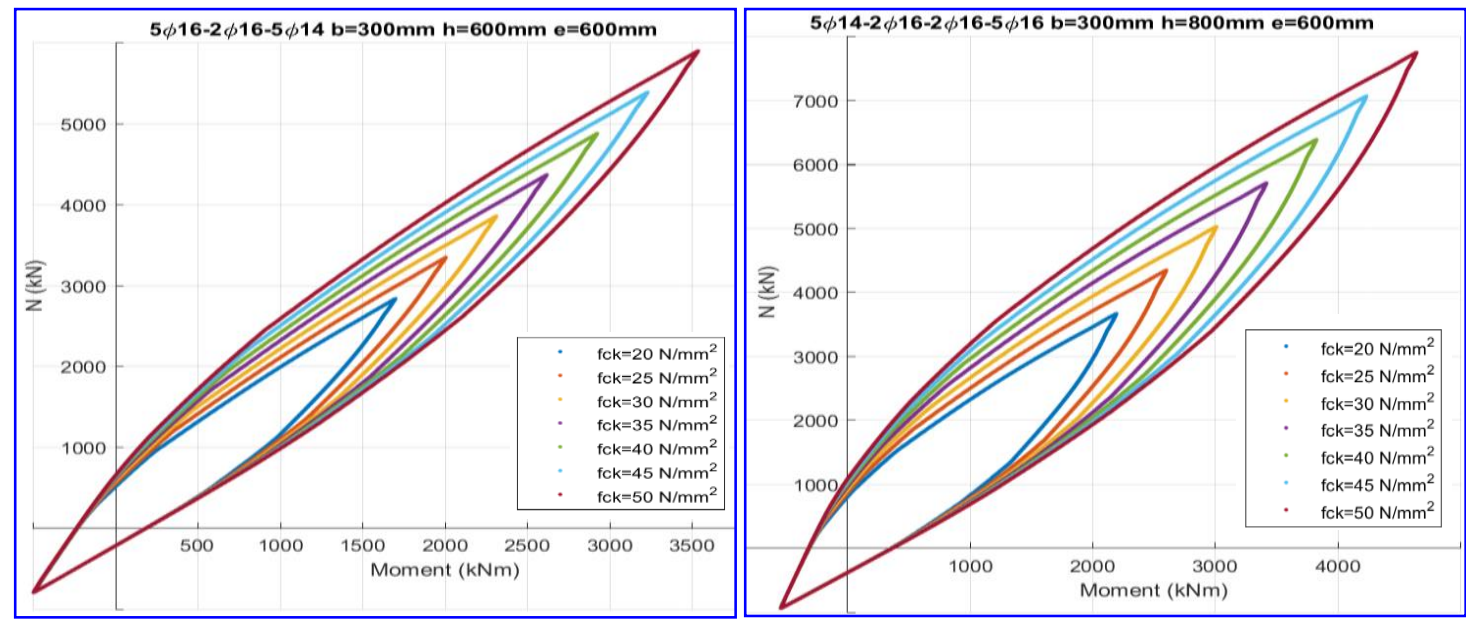

Figure 11. Interaction diagrams for column with unsymmetrical longitudinal reinforcements under combined bending moment and axial load

As shown in Figure $11 \mathrm{~N}-\mathrm{M}$ interaction diagram, it is seen that the axial strength and the moment carrying capacity increases with the cross section area and the concrete strength increase. This interaction diagram represents the design strength of eccentrically loaded column with known section properties and different concrete classes. The axial compression force generated under the vertical loads $(\mathrm{g}+\mathrm{q})$ in the column sections will not be greater than $\mathrm{N}_{\mathrm{d}, \max }=0.40 \mathrm{f}_{\mathrm{ck}} \mathrm{bh}$, and the axial compression force generated under the vertical loads in the shear wall cross sections will not be greater than $\mathrm{N}_{\mathrm{d}, \max }=0.25 \mathrm{f}_{\mathrm{ck}} \mathrm{bh}$ (TEC2018). The gross cross-section area of the column and the maximum axial compression force calculated under the joint effect of $\mathrm{N}_{\mathrm{dm}}$ vertical loads and earthquake loads should provide the $\mathrm{N}_{\mathrm{dm}}=0.50 \mathrm{f}_{\mathrm{ck}} \mathrm{bh}$ criteria (TEC2007). In all columns, $\mathrm{N}_{\mathrm{d}}=0.6 \mathrm{f}_{\mathrm{ck}} \mathrm{bh}$ condition should be provided (TS500). Axial load level of the column section is large in TS500 compared to TEC2007. Even at TEC2018, the column axial load level is reduced by $20 \%$ compared to TEC2007. The graphs used in the calculation of the reinforced concrete columns in the application are 
dimensionless N-M diagrams (Figure 12). Dimensioning of reinforced concrete columns at desired ductility level requires drawing of N-M diagrams. For a given column cross section under eccentric load for reinforcement plans in compression and tension sides $A_{\mathrm{s} 1}$ and $A_{\mathrm{s} 2}$ are all reasonable and form the reinforcement scheme boundaries.

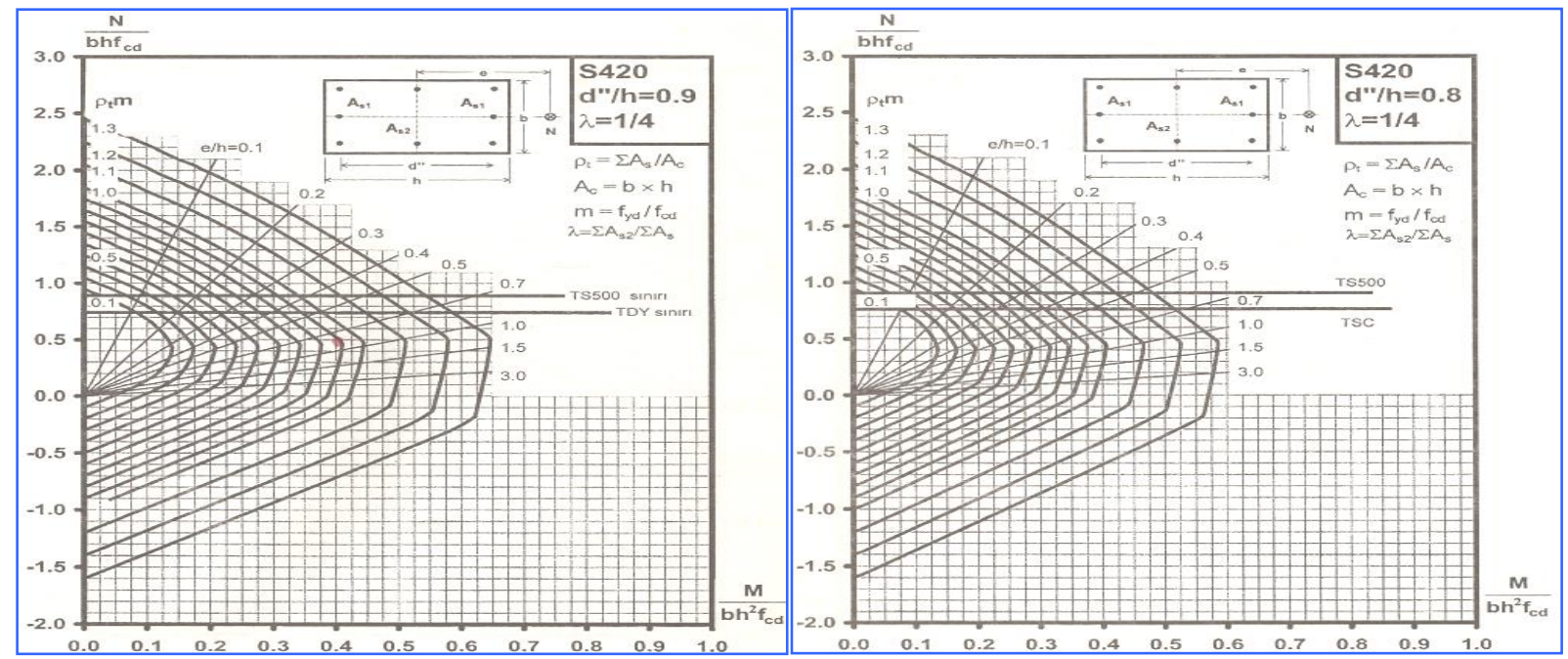

Figure 12. Interaction diagrams for rectangular RC columns when bars are placed along all four sides.

\section{MOMENT CURVATURE RELATIONSHIP IN REINFORCED CONCRERE COLUMNS}

Moment curvature envelops of the specimens were used to calculate the curvature ductility capacity. Although the ductility zone is determined from the N-M interaction diagrams of the reinforced concrete sections, the ductility ratio is not determined, so for a cross-section "Moment-Curvature" (MK) relationship must be obtained. The real behavior of a reinforced concrete section can be traced from $\mathrm{M}-\mathrm{K}$ curves obtained from experimental data. The $\mathrm{M}-\mathrm{K}$ curves determine the load carrying capacity of the section for current and expected loads and rotation capacity. Additionally, M-K curve is critical for the designer to known to do actual dimensioning for following reasons:

1. Display clear indication of the "behavior under load",

2. Determine the strength and the rotation capacity of the section,

3. Determination of the true deformation by integrating twice.

Change of deformations in rectangular RC sections due to bending moment is shown in Figure 13.
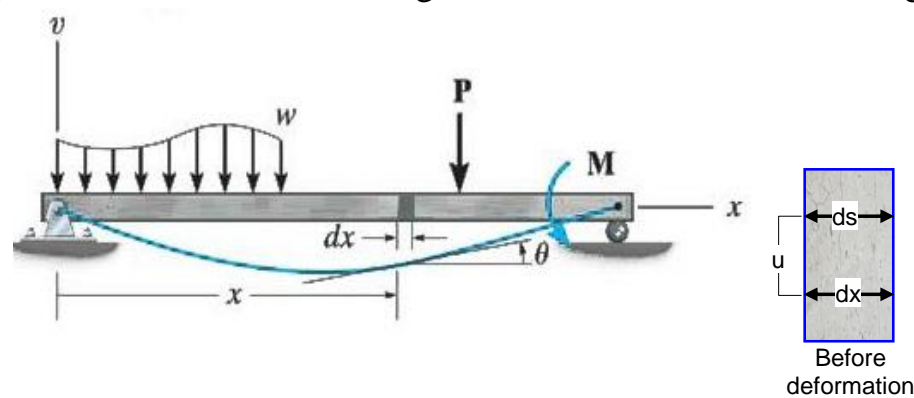

$\mathrm{ds}=\mathrm{dx}=\rho \mathrm{d} \theta$

$d s^{\prime}=(\rho-u) d \theta$

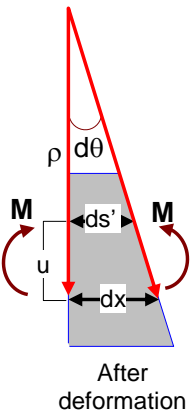

Figure 13. Deformation of the beam and cross section

The curvature $(\mathrm{K})$, which is defined as a unit rotation (rotation per unit length) angle, is given in Equation 9. 


$$
\varepsilon=\frac{\mathrm{ds}^{\prime}-\mathrm{ds}}{\mathrm{ds}} \quad \frac{1}{\rho}=\frac{\mathrm{d} \theta}{\mathrm{dx}}=-\frac{\varepsilon}{\mathrm{u}}=\mathrm{K}
$$

M-K relations of a section under combined bending depend on the axial load levels. That is, the moment-curvature relationships under high and low axial load levels are different for a cross section under combined bending. The region under the M-K curve shows the energy absorption capacity of the cross-section. Moreover, ductility presents the ability to enable large deformation without a big fall in the load carrying capacity. The axial load must be low in situations where the absorbing of the energy generated by the earthquake is critical. After reinforcement reaching the yield moment in the section, the bending stiffness approaches zero and the curvature rapidly increases at a moment that remains almost constant. In M-K curve, the curvature value against the yielding of the tensile reinforcement remains linear up to $\mathrm{K}_{\mathrm{y}}$ and moment remains constant under increasing curvature after this point. When the curvature value corresponding to the moment of rupture reaches $K_{u}$, the concrete in the outermost compression section reaches the crushing point and the concrete is crushed and the momentum carrying capacity of the cross section is exhausted.

For a cross-section $\mathrm{M}-\mathrm{K}$ relationship, a value of $\varepsilon_{\mathrm{ci}}$ is taken from the concrete $\mathrm{f}_{\mathrm{c}}-\varepsilon_{\mathrm{c}}$ curve (Figure 14 ), and $\mathrm{c}$ neutral axis depth for this $\varepsilon_{\mathrm{ci}}$ is estimated to determine whether the reinforcement yield in this section. The internal forces of the section are calculated from following equation for concrete: $F_{\mathrm{ci}}=\alpha \cdot \beta \cdot c \cdot f_{\mathrm{ck}} \cdot b_{\mathrm{w}}$, for yielded reinforcement: $\mathrm{F}_{\mathrm{si}}=\mathrm{f}_{\mathrm{yd}} \cdot \mathrm{A}_{\mathrm{si}}$, and for non-yielded reinforcement: $\mathrm{F}_{\mathrm{si}}=\varepsilon_{\mathrm{si}} \cdot \mathrm{f}_{\mathrm{si}} \cdot \mathrm{A}_{\mathrm{si}} \cdot$ In this study, $\beta$ and $\alpha$ coefficients are used according to $\varepsilon_{\mathrm{ci}}$ variation for obtaining the M-K curve [1113-17]. If the axial force of the element for which the $M-K$ curve is to be calculated is $N_{d}=0$, the estimated $c$ value for $\varepsilon_{c i}$ is changed until $F_{c}=F_{t}$ or $N=F_{c}-F_{t}=0$. When $N=F_{c}-F_{t}=0$ is met, $M$ is calculated with respect to the section plastic centroid and $\mathrm{K}$ curvature value is calculated by Equation 9. If the axial force of the element for which the $\mathrm{M}-\mathrm{K}$ curve is to be calculated is $\mathrm{N}_{\mathrm{d}} \neq 0$, the estimated $\mathrm{c}$ value for $\varepsilon_{\mathrm{ci}}$ is changed until $\mathrm{F}_{\mathrm{c}}-\mathrm{F}_{\mathrm{t}}=0$. When $\mathrm{F}_{\mathrm{c}}-\mathrm{F}_{\mathrm{t}}=0$, $\mathrm{M}$ is calculated with respect to the section plastic centroid and $K$ curvature value is calculated by Equation 9 . For both $N_{d} \neq 0$ and $N_{d}=0$ cases, these operations are carried out to scan the section height and the concrete $\mathrm{f}_{\mathrm{c}}-\varepsilon_{\mathrm{c}}$ curve. In Figure 14 , the M-K curve is obtained for the given reinforcement arrangement and section geometry.

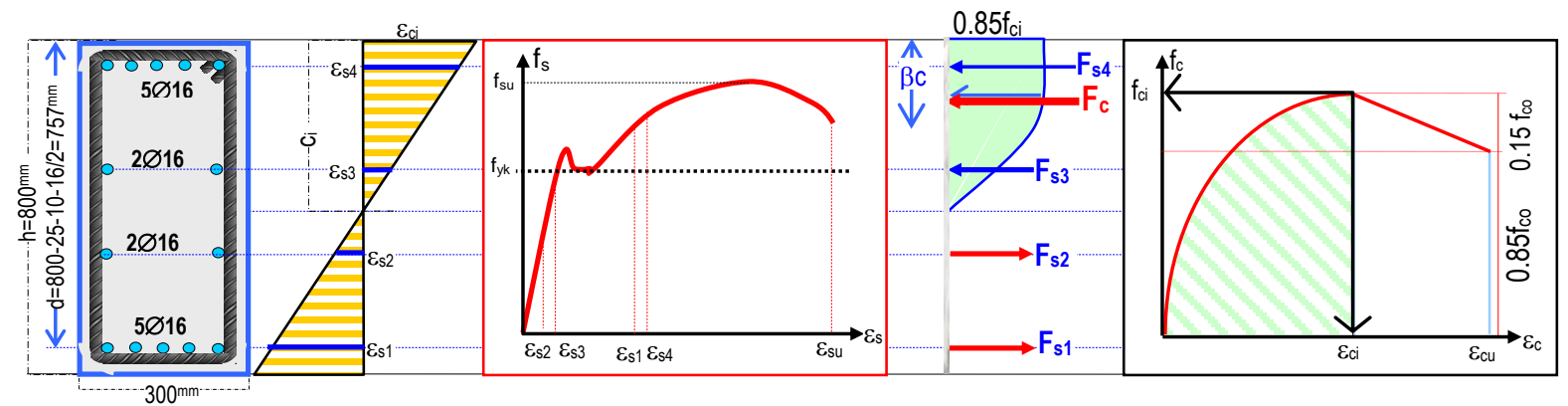

Figure 14. Section strains, stresses and concrete and steel strain-stress curves

The numerical example was carried out for different $\varepsilon_{\mathrm{ci}}$ values of $0.0005,0.001,0.002,0.003$, and 0.004 , and the M-K relationship are plotted in Figure 15. Since $\mathrm{f}_{\mathrm{c}^{-}} \varepsilon_{\mathrm{c}}$ curve is non-linear for concrete before crushing and $\mathrm{f}_{\mathrm{s}}-\varepsilon_{\mathrm{s}}$ is non-linear the reinforcement after yielding, high-accuracy calculations must be made to achieve true M-K values. Different methods are used for these calculations. The M-K curves for points A, B, C, D and E in the N-M diagram on Figure 8 are drawn in the Figure 15. 


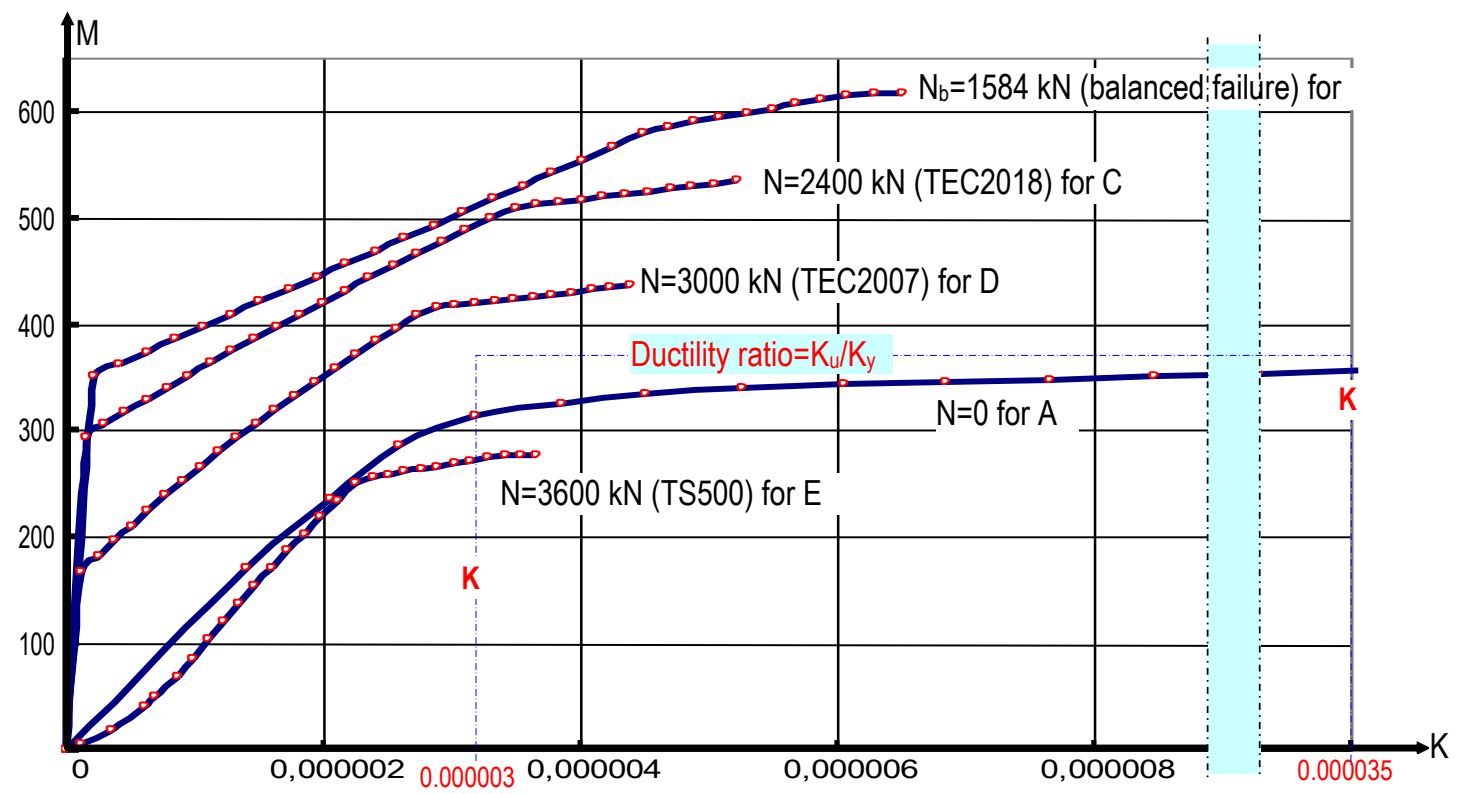

Figure 15. Moment-curvature curves for different axial forces in a rectangular column section

Evaluation of the M-K curves in the figure above reveals that;

1. The curvature decreases as the axial load level increases,

2. The curvature increases as the moment of the cross section increases,

3. The ideal case occurs where $\mathrm{N}=0$.

Therefore, it is desirable to keep the axial load levels of the columns as low as possible while dimensioning the columns. This situation is controlled by codes.

\section{CONCLUSION}

Reinforced concrete columns ability to exhibit ductile behavior at the desired level and the energy consumption capacity depends on the axial load level. Therefore, the capacity of the column can be determined directly plotted on N-M interaction diagram. As shown in Figure 8, the increase in the axial force in the column section increases the moment capacity up to the balanced case, and decreases the moment capacity after the balanced case. This balanced case indicates that the failures at the points below are ductile, and those at the points above are brittle for the reinforced concrete columns. The TEC2018 code introduces an upper limit on column axial load capacity as shown in Figure 8. One of the reasons for this criteria is dimensioning the columns in a way as to consume the earthquake loads with the plastic joints to be formed first in the beams and then in the columns. TEC2018 requires that the joining beam bending moments acting at the faces of the beams are always smaller than the joining bending moments acting at the faces of the columns in beam column joints. Although TEC2018 does not predict an increase in the carrying capacity of the beams, it requires a reduction in the upper limit of the column axial load by $20 \%$ compared to TEC 2007 .

Figure 15 shows that the ductility ratio decreases as the axial load level increase in reinforced concrete columns. As a result of the study, the ductility ratio becomes approximately 12 if the column axial load is $\mathrm{N}=0$ and the ductility ratio becomes 1.59 for $\mathrm{N}=3600 \mathrm{kN}$, which is the axial load upper limit of TS500. The ductility ratios can be calculated from Figure 15 for the axial force upper limits in the code and other axial force values. 
As a result of the study, the axial compression and tensile force carrying capacity of the columns were found to be related to column section and the concrete strength. Therefore, it can be more appropriate to use of the reinforced shear wall instead of the columns at the point where the axial load is large. Reinforced concrete shear wall increase the stiffness especially under earthquake forces and consequently increase the load carrying capacity decrease the horizontal displacement of the columns. As shown in Figure 9, eccentricity is a parameter that determines the behavior of the columns. In TEC2018, it is required to account for a minimum eccentricity value even if the true eccentricity is zero. Thus, the load bearing capacity of the columns is calculated according to the axial force and moment. The convergence of the beam and column axes will contribute to the ductility of the column while reducing the eccentricity. In other words, especially in the edge and corner columns, the beam loads applying the edge of the columns negatively affects the column behavior.

\section{REFERENCES}

[1] ACI Committee 318. Building Code Requirements for Structural Concrete (ACI 318-14). American Concrete Institute, Farmington Hills, MI, 2014.

[2] FEMA 356. Prestandard and Commentary for the Seismic Rehabilitation of Buildings. FEMA, Washington, DC, USA, 2000.

[3] EC8. Design Provisions for Earthquake Resistance of Structures. Pub. ENV-2003-2, Comite Europeen de Normalization, Brussels, 2003.

[4] TEC2007. Deprem Bölgelerinde Yapılacak Binalar Hakkında Yönetmelik. Bayındırlık ve İskan Bakanlığı (in Turkish), Ankara, 2007.

[5] TEC2018. Türkiye Bina Deprem Yönetmeliği. Çevre ve Şehircilik Bakanlığı (in Turkish), Ankara, 2018.

[6] Furlong RW. Concrete columns under biaxial eccentric thrust. ACI Journal 1979; 1093-1118.

[7] Hsu CT. Biaxial loaded L-shaped reinforced concrete columns. ASCE J Struct Eng 1985; 111(12): 2576-2595.

[8] Hsu CT. Channel-shaped reinforced concrete compression members under biaxial bending. ACI Struct J 1987; 84: 201-211.

[9] Hsu CT. T-shaped reinforced concrete members under biaxial bending and axial compression. ACI Struct J 1989; 86(4): 460-468.

[10] Rangan BV. Strength of reinforced concrete slender columns. ACI Struct J 1990. 87(1): 32-38.

[11] Ersoy U Özcebe G. Betonarme. 5. Basım, Ankara: Seçkin Yayıncılık, 2017.

[12] Berktay İ. Betonarme I, Taşıma Gücü ve Kesit Hesapları.3. Basım, İstanbul: İnşaat Mühendisleri Odas1, 2003.

[13] Orbay A. Betonarme I. İstanbul: Birsen Yayınevi, 2005.

[14] TS 500, Betonarme Yapıların Tasarım ve Yapım Kuralları, Türk Standartları Enstitüsü (in Turkish), Ankara, 2000. 
Günaydın and Gökdemir / Anadolu Univ. J. of Sci. and Technology A-Appl. Sci. And Eng. 19 (2) - 2018

[15] Jia Y, Chang P and Sun J. Specified domain in nu-mu interaction diagram for logical judgment in numerical analysis on compression reinforced concrete members. The Open Construction and Building Technology Journal, 2014; 8: 400-405.

[16] McCormac JC and Brown RH. Design of Reinforced Concrete. John Wiley, 2014.

[17] Ersoy U. Özcebe G. Sarılmış betonarme kesitlerde moment-eğrilik ilişkisi analitik bir irdeleme, Teknik Dergi 1998; 9(44): 1799-1827. 